Article in:

Bioethical Inquiry, Vol. 12, $\mathrm{n}^{\circ} 1,2015$. An interdisciplinary forum for ethical and legal debate

ISSN 1176-7529

Bioethical Inquiry

DOI 10.1007/s11673-015-9635-7

"The final

publication is available at link.springer.com".

\title{
Between Palliative Care and Euthanasia
}

[author(s)] Tom Mortier; René Leiva; Raphael Cohen-Almagor; Willem Lemmens

[author affiliations]

Tom Mortier [corresponding author]

Faculty of Management and Technology, Faculty of Health and Welfare, University Colleges

Leuven-Limburg

Herestraat 49

3000 Leuven

Belgium

e-mail: tom.mortier@ucll.be

\section{René Leiva}

Department of Family Medicine, University of Ottawa

\section{Raphael Cohen-Almagor}

School of Politics, Philosophy and International Studies, University of Hull

\section{Willem Lemmens}

Head of the Centre for Ethics, University of Antwerp

Keywords Palliative care; Euthanasia; Belgium 
Abstract In 2002, Belgium became the second country in the world to legalize euthanasia. A few studies dealing with the Belgium euthanasia practices have been published, based on a survey given to a sample of physicians and nurses. These studies have implicitly proposed the practice of euthanasia as a medical act. Moreover, an article published in the Journal of Bioethical Inquiry argued that the Belgian experiment concerning medical end-of-life decisions is unique in the world and that the Belgian palliative care system, including euthanasia, should serve as a role model for the rest of the world. This conclusion is rather an overstatement. We analyzed the latest data provided by the Belgian Federal Euthanasia Commission. Almost 40 percent of the patients who received euthanasia did not see a palliative care specialist nor interacted with a palliative care team. Moreover, the charts of the patients euthanized cannot be reviewed since they are anonymous and nothing is known about the unreported cases. Professional carefulness dictates cautious conclusions.

In 2002, Belgium was the second country in the world to legalize euthanasia following the Netherlands. Since then, a few studies dealing with Belgium euthanasia practices have been published that are based on a survey given to a sample of physicians and nurses (Deliens et al. 2000; Bilsen et al. 2009; Smets et al. 2010). All these studies from the past decade have implicitly proposed the practice of euthanasia as a medical act. Moreover, the last article published in this journal argued that the Belgian experiment concerning medical end-of-life decisions is unique in the world and that the Belgian palliative care system, including euthanasia, should serve as a role-model for the rest of the world (Bernheim et al. 2014).

The Belgium law provides a definition for euthanasia which lacks the analytical precision to apply it to medical studies (Commission Fédérale de Contrôle et d'Évaluation de l'Euthanasie 2014). When analyzing the latest data provided by the Belgian Federal Euthanasia Commission (years 2012-2013), we see that only 40 percent $(1,283$ out of 3,239) of the euthanized patients had a visit by a palliative care team, barely 12 percent $(396$ out of 3,239$)$ had a visit by a palliative care specialist, and just 9 percent $(307$ out of 3,239) were consulted by a psychiatrist (Commission Fédérale de Contrôle et d'Évaluation de l'Euthanasie 2014). Thus almost 40 percent of the patients who received euthanasia did not see a palliative care specialist nor interacted with a palliative care team. The conclusion that Belgium is a palliative care role model 
for the world is an overstatement. Moreover, as previously admitted by well-known Belgium euthanasia researchers, the charts of the patients euthanized cannot be reviewed since they are anonymous (Chambaere et al. 2014). Finally, nothing is known about the unreported cases (Leiva et al. 2014). Professional carefulness dictates cautious conclusions.

Legalizing euthanasia has proven to be a dangerous experiment. The World Medical Association (WMA) declared that "euthanasia ... is unethical and must be condemned by the medical profession” (World Medical Association 2013, \5). Dr. André Wynen, the Belgian doctor who was the Secretary General of the World Medical Association, saw the dangers of legalizing euthanasia, and therefore he strongly opposed the practice. He was instrumental in the adoption of the declaration against euthanasia by the WMA. Wynen thought that legalizing euthanasia would result in rationing health care (Stafford 2007). Dr. Dame Cicely Saunders, founder of the modern hospice movement, always maintained that euthanasia runs contrary to the true ethos of palliative care (Saunders 1976). Bilsen et al. (2009) found that the enactment of the Euthanasia Act was followed by an increase in all types of medical end-of-life practices, with the exception of the use of life-ending drugs without explicit request that, of course, is a most troubling lingering problem.

The Belgian law on euthanasia created many ethical problems and introduced a new form of paternalism. Looking at the short history of euthanasia in Belgium may lead us to think that there is something intoxicating about the practice that blinds the eyes of decision-makers, leading them to press forward further end-of-life practices without paying ample attention to caution. One cautionary barrier after the other is removed to allow greater scope for euthanasia. The logic of the 2002 Euthanasia Act that spoke of adults or emancipated minors lost its grounds in 2014 when Belgians extended the law to all minors. Although some patients are euthanized without explicit request (1.8 percent of all deaths in 2010) (Chambaere et al. 2010), Belgians are not hard-pressed to push for more stringent control mechanisms. Quite the opposite: the scope of tolerance toward the practice of euthanasia is enlarged, so as yesterday's red light becomes obsolete today, and as soon as that red light is removed, practitioners and lawmakers are already debating further steps and other groups to be included within the more liberal euthanasia policy - young patients, patients who are tired of life, and now Belgians are discussing euthanizing patients with dementia (Cohen-Almagor 2013,2015). This is quite astonishing as human lives are at stake. What is required is a careful study, accumulation of knowledge and 
data, and addressing the above concerns. This exercise should lead to an analysis of the current euthanasia law, whereby politicians, the medical profession, and juridical authorities soberly reflect on the developments that have taken place since 2002. Haste makes waste.

\section{References}

Bernheim, J.L., W. Distelmans, A. Mullie, and M.A. Ashby. 2014. Answers on the Belgian model of integral end-of-life care: Experiment? Prototype? Journal of Bioethical Inquiry 11(4): 507-529.

Bilsen, J., J. Cohen, K. Chambaere, et al. 2009. Medical end-of-life practices under the Euthanasia Law in Belgium. The New England Journal of Medicine 361(11): 1119-1121.

Chambaere, K., J. Bilsen, J. Cohen, B.D. Onwuteaka-Philipsen, F. Mortier, and L. Deliens. 2010. Physician-assisted deaths under the Euthanasia Law in Belgium: A population-based survey. Canadian Medical Association Journal 182(9): 895-901.

Chambaere, K., J.L. Bernheim, J. Downar, and L. Deliens. 2014. Characteristics of Belgian "lifeending acts without explicit patient request": A large-scale death certificate survey revisited. CMAJ Open 2(4): E262-E267. Online appendices (reviewers' comments) http://cmajopen.ca/content/supp1/2014/12/02/2.4.E262.DC1/Reviewer_comments.pdf. Accessed January 25, 2015.

Cohen-Almagor, R. 2013. First do no harm: Pressing concerns regarding euthanasia in Belgium. The International Journal of Law and Psychiatry 36(5-6): 515-521.

Cohen-Almagor, R. In press. First do no harm: Euthanasia of patients with dementia in Belgium. Journal of Medicine and Philosophy.

Commission Fédérale de Contrôle et d'Évaluation de l'Euthanasie. 2014. Service Public Fédéral (SPF) Santé publique, Sécurité de la Chaîne alimentaire et Environnement. Brussels: Secrétariat de la Commission. http://www.health.belgium.be/eportal/Healthcare/Consultativebodies/Commissions/Eutha nasia/Publications/index.htm. Accessed January 25, 2015.

Deliens, L., F. Mortier, J. Bilsen, et al. 2000. End-of-life decisions in medical practice in Flanders, Belgium: A nationwide survey. The Lancet 356(9244): 1806-1811.

Leiva, R.A., T. Mortier, G. Casteur, and T. Lau. 2014. Re: Characteristics of Belgian "lifeending acts without explicit patient request": A large-scale death certificate survey 
revisited. CMAJ, December 18.

http://www.cmaj.ca/content/186/18/1368.full/reply\#cmaj_el_726624. Accessed January 25, 2015.

Saunders, C. 1976. Care of the dying-1. The problem of euthanasia. Nursing Times 72(26): 1003-1005.

Smets, T., J. Bilsen, J. Cohen, M.L. Rurup, F. Mortier, and L. Deliens. 2010. Reporting of euthanasia in medical practice in Flanders, Belgium: Cross sectional analysis of reported and unreported cases. British Medical Journal 341: c5174. doi:http://dx.doi.org/10.1136/bmj.c5174.

Stafford, N. 2007. André Wynen. The Lancet 370 (9591): 930. doi:http://dx.doi.org/10.1016/S0140-6736(07)61432-9.

World Medical Association. 2013. WMA resolution on euthanasia. http://www.wma.net/en/30publications/10policies/e13b/. Accessed January 25, 2015. 